\title{
The Effect of Gonadotropin-Releasing Hormone Analogue on Final Adult Height in Children with Idiopathic Short Stature
}

\author{
Nahla Khawaja ${ }^{a}$ Hala Owaineh ${ }^{a} \quad$ Anwar Batiehab $^{b}$ Oraib Frahid $^{a}$ \\ Mohammed EL-Khateeb ${ }^{a}$ Kamel M. Ajlouni ${ }^{a}$ \\ a The National Center (Institute) for Diabetes, Endocrinology and Genetics, University of Jordan, Amman, Jordan; \\ ${ }^{b}$ Department of Community Medicine, Jordan University of Science and Technology, Irbid, Jordan
}

\section{Significance of the Study}

- Idiopathic short stature (ISS) is a worrisome isolated physical characteristic in a healthy child. The evidence to support the use of gonadotropin-releasing hormone analogue as a growth-promoting therapy in children with ISS is lacking. Our clinical case series study has shown that gonadotropinreleasing hormone analogues have a potential in improving final adult height in adolescent females with this condition.

\section{Keywords}

Gonadotropin-releasing hormone analogues · Short stature · Final adult height

\section{Abstract \\ Objective: To assess final adult height $(\mathrm{FAH})$ in children with short stature treated with gonadotropin-releasing hormone analogue (GnRHa). Methods: All patients with idiopathic short stature (ISS) with normally timed puberty and a Tanner stage between 2 and 3, who achieved their FAH between 2005 and 2015, were included in this clinical historical cohort study. Height gain, FAH, and mid-parental height of 28 chil- dren with ISS who received GnRHa treatment for $1.8 \pm 1.0$ years to delay their puberty were compared to 31 untreated children. Results: The FAHs of the treated and the untreated girls were $151.3 \pm 5.1$ and $146.8 \pm 3.8 \mathrm{~cm}(p=0.01)$, respec- tively. The FAHs of the treated and the untreated boys were}

\section{KARGER}

E-Mail karger@karger.com www.karger.com/mpp
(C) 2019 The Author(s) Published by S. Karger AG, Basel

Karge Open access

This is an Open Access article licensed under the Creative Commons Attribution-NonCommercial-4.0 International License (CC BY-NC) (http://www.karger.com/Services/OpenAccessLicense), applicable to the online version of the article only. Usage and distribution for commercial purposes requires written permission.
$156.4 \pm 4.7$ and $152.3 \pm 5.7 \mathrm{~cm}(p=0.111)$, respectively. The height gain in the treated and the untreated girls was $1.6 \pm$ 7.8 and $-3.6 \pm 5.7 \mathrm{~cm}(p=0.036)$, respectively. Height gain in the treated and the untreated boys was $-5.1 \pm 13.6$ and -11.5 $\pm 8.4 \mathrm{~cm}(p=0.171)$, respectively. Conclusion: $\mathrm{GnRHa}$ therapy has a modest effect in improving $\mathrm{FAH}$ in adolescent females with ISS but not in boys. @ 2019 The Author(s)

Published by S. Karger AG, Basel

\section{Introduction}

Short stature is a worrisome condition for both parents and children all over the world. It constitutes a psychosocial burden in the form of impaired emotional well-being and psychological adaptation of the affected children [1]. As these children may feel physically weaker than their peers, parents tend to overprotect them from social adver- 
sities [2]. However, true psychopathology is unusual with high variability in inter-individual adaptation to short stature, as patients' social competence and behavioral adaptation were comparable to their classmates and population-based norms [3]. Socioeconomic factors, rather than stature, predict academic and psychosocial outcomes among community cohorts of short healthy children [4].

Idiopathic short stature (ISS) is found to be an isolated physical characteristic in an otherwise healthy child. It is defined as a height that is more than 2 SDs below the mean height for an age- and sex-matched population without evidence of a disease and normal levels of stimulated growth hormone (GH) [5]. Around $80 \%$ of children evaluated for short stature by pediatric endocrinologist are labelled as having ISS [6].

Final adult height (FAH) is determined by several factors such as genetic predisposition, GH secretion, nutritional status, onset and duration of puberty, and total height attained during puberty [7]. Pubertal growth spurt is characterized by a prompt and intense increase in height that occurs during the adolescent stage of the human life cycle and precedes fusion of epiphyseal growth plates. The onset of this spurt is variable between individuals and populations, and is sex-dependent. It starts earlier in girls with shorter duration in comparison to boys. Around $20 \%$ of adult height is achieved during the pubertal growth spurt [8].

Different therapeutic approaches have been investigated to improve the statural outcome in children with ISS [9-11]. However, the best therapeutic strategy is still a matter of debate $[10,11]$. As each modality is confronted by challenges in predicting and defining the adequate growth response, the extent of physical and psychological disability from short stature is used to determine the eligibility for growth-promoting therapy in children with ISS $[3,4,10,11]$.

Gonadotropin-releasing hormone analogue ( $\mathrm{GnRHa}$ ) therapy is a well-established modality of treatment in children with central precocious puberty (CPP) [12]. GnRHa therapy not only retards pubertal progression but also has the potential to delay epiphyseal fusion and prolong the period of linear growth. The use of GnRHa in children with CPP has clearly demonstrated favorable effects in terms of restoring genetic growth potential and improving FAH [12].

The association between untreated hypogonadism, aromatase deficiency in males and tall stature had shed light on the effect of pubertal delay on height prognosis $[13,14]$. The use of GnRHa therapy for the promotion of growth in healthy short children had created significant controversy based on statural growth and side effects [1518]. Although evidence to support the use of GnRHa as a growth-promoting therapy is lacking, systemic examination of GnRHa prescribing practices showed that $26.5 \%$ of children were treated for short stature in the context of normal puberty [19]. Based on our previous retrospective study that assessed the FAH in $43 \mathrm{GnRHa}$ treated CPP children and 13 untreated children [20], we conducted this historical cohort study to assess whether manipulating puberty using GnRHa could increase height in Jordanian children with ISS and normally timed puberty as it does in our patients with precocious puberty [20].

\section{Subjects and Methods}

Our historical cohort study was conducted after obtaining approval from the Ethics Committee of the National Center for Diabetes Endocrinology and Genetics, which is accredited by the National Ethics Committee. Also, the study was conducted in accordance with the Declaration of Helsinki. As we used routinely generated data with no identifying information, the study carries no harm whatsoever to patients. Data were used only for scientific purposes.

Based on the therapeutic policy of the National Center for Diabetes Endocrinology and Genetics in Jordan, GnRHa was offered to all children with ISS with normally timed puberty and was managed according to a predesigned protocol as an experimental treatment. Children diagnosed with ISS (Z-score that is $<2$ SD score below the median height for that age and sex), had normally timed puberty, had a Tanner stage between 2 and 3, were given $3.75 \mathrm{mg}$ GnRHa (Triptorelin SR, Decapeptyl, Ipsen, Biotech) intramuscular injections monthly for at least 1 year to suppress their puberty, and achieved their FAH between 2005 and 2015 were eligible for inclusion in this study. Children with hypothyroidism, renal disease, celiac disease, congenital adrenal hyperplasia, closed epiphyseal plates, primary bone disease, and dysmorphic features were excluded. However, no data on birth length could be obtained to exclude small-for-gestational age children. Eligible children underwent either Insulin Tolerance Test or Glucagon Stimulation Test to exclude GH deficiency. An informed consent was obtained from the parents of children before starting GnRHa treatment. Children whose caregivers refused GnRHa therapy were included in the study as a control group.

A total of 59 patients were enrolled in this study. Twenty-eight children with ISS ( 21 girls and 7 boys) were given $3.75 \mathrm{mg} \mathrm{GnRHa}$ (Triptorelin SR, Decapeptyl, Ipsen, Biotech) administered by intramuscular injection every month. On the other hand, 31 children with ISS (14 girls and 17 boys) their caregivers refused GnRHa therapy, comprised the control group.

Height, weight and pubertal stage were evaluated initially and regularly every 3 months for both groups. After discontinuation of GnRHa, both groups were evaluated at each subsequent year until FAH was attained. The measurement of FAH was taken when growth velocity was $<1.5-2 \mathrm{~cm} /$ year, or when bone age (BA) was 14.5 years in girls and 16.5 years in boys [21]. Height was measured with a Harpenden stadiometer, and was calculated as the average of 3 measurements to the nearest $0.5 \mathrm{~cm}$ while the patient was 
standing without shoes maintaining a vertical stature and the

ISS children with ISS (14 girls and 17 boys) who did not Table 1. Baseline characteristics of GnRHa-treated and -untreated idiopathic short stature children by gender

\begin{tabular}{|c|c|c|c|c|c|c|}
\hline \multirow[t]{2}{*}{ Variables } & \multicolumn{3}{|l|}{ Females } & \multicolumn{3}{|l|}{ Males } \\
\hline & $\begin{array}{l}\text { treated } \\
(n=21)\end{array}$ & $\begin{array}{l}\text { untreated } \\
(n=14)\end{array}$ & $p$ value & $\begin{array}{c}\text { treated } \\
(n=7)\end{array}$ & $\begin{array}{l}\text { untreated } \\
(n=17)\end{array}$ & $p$ value \\
\hline Age at presentation, years & $10.9 \pm 1.4$ & $11.6 \pm 1.3$ & 0.155 & $12.6 \pm 1.7$ & $13.8 \pm 1.3$ & 0.066 \\
\hline Height at presentation, $\mathrm{cm}$ & $134.0 \pm 8.0$ & $135.9 \pm 9.8$ & 0.548 & $134.7 \pm 8.6$ & $141.1 \pm 6.8$ & 0.064 \\
\hline Height-SD score at presentation & $-2.1 \pm 1.4$ & $-2.4 \pm 1.3$ & 0.534 & $-3.1 \pm 0.7$ & $-3.0 \pm 1.0$ & 0.827 \\
\hline $\mathrm{MPH}, \mathrm{cm}$ & $155.3 \pm 6.3$ & $155.1 \pm 4.4$ & 0.900 & $170.8 \pm 3.3$ & $167.7 \pm 4.7$ & 0.132 \\
\hline $\mathrm{PAH}$ & $149.6 \pm 7.6$ & $150.5 \pm 6.5$ & 0.711 & $161.5 \pm 12.2$ & $163.8 \pm 8.3$ & 0.592 \\
\hline Bone age at presentation, years & $10.9 \pm 1.2$ & $11.5 \pm 1.8$ & 0.249 & $11.6 \pm 2.7$ & $12.6 \pm 1.1$ & 0.216 \\
\hline
\end{tabular}

GnRHa, gonadotropin-releasing hormone analogue; MPH, mid parental height; PAH, predicted adult height.

blades of the shoulders were parallel. An experienced radiologist using a left hand and wrist radiograph based on Greulich and Pyle atlas [22] determined BA. Pubertal development was assessed according to the Marshal and Tanner staging system [23, 24]. Predicted adult height (PAH) at the start of treatment was calculated using the Bayley and Pinneau method [25]. Mid-parental height (MPH) is the average of the parental heights minus $6.5 \mathrm{~cm}$ for girls and plus $6.5 \mathrm{~cm}$ for boys $(6.5 \mathrm{~cm}$ being half the mean gender difference in adult height).

To assess the effectiveness of GnRHa therapy in children with ISS, the following outcome measures were used: $\mathrm{FAH}$, height gain (the difference between FAH and PAH at initiation of GnRHa), the difference between $\mathrm{FAH}$ and $\mathrm{MPH}$, and the proportion of patients who attained their PAH and $\mathrm{MPH}$.

\section{Statistical Analysis}

The Statistical Package for Social Sciences SPSS ${ }^{\circledR} 19$ (SPSS, Inc., Chicago, IL, USA) was used to enter and analyze data. Frequencies and percentages were obtained for categorical variables. Continuous variables were presented as means \pm SDs. To assess the significance of observed differences between GnRH-treated and untreated groups, we used the independent $t$ test for continuous variables and the chi-square test or Fisher's exact test for categorical variables. Percentages of both GnRHa-recipients and non-recipients who achieved PAH and MPH were obtained. Potential confounding was dealt with through performing multivariate linear regression. Height gain in this study was the dependent variable, and treatment group together with other potential confounders were independent variables. The most parsimonious model that best fitted the data was reported.

\section{Results}

\section{Baseline Characteristics}

A total of 59 patients were enrolled in this study including 28 children with ISS ( 21 girls and 7 boys) who were treated with GnRHa to delay their puberty and 31 receive treatment. The mean duration of treatment was $1.8 \pm 1.0$ years $(1.3 \pm 0.3$ years for boys vs. $2.0 \pm 1.1$ years for girls; $p=0.182$ ). The minimum duration of treatment was 1 year and the maximum duration of treatment was 4 years.

The 2 groups showed imbalance in terms of sex distribution as the proportion of females in the treated group outnumbered the proportion of females in the untreated group.

The main auxological characteristics of GnRHa in the treated and the untreated groups according to gender are depicted in Table 1. At presentation, there were no significant differences between the treated and the untreated girls with respect to chronological age (10.9 vs. 11.6 years), BA (10.9 vs. 11.5 years), height ( 134.0 vs. $135.9 \mathrm{~cm})$, Height-SD score ( -2.1 vs. -2.4$)$, PAH (149.6 vs. 150.5 $\mathrm{cm})$, and $\mathrm{MPH}$ (155.3 vs. $155.1 \mathrm{~cm}$ ).

The baseline auxological parameters for the treated and the untreated boys were similar for chronological age (12.6 vs. 13.8 years), BA (11.6 vs. 12.6 years), height (134.7 vs. $141.1 \mathrm{~cm})$, Height-SD score (-3.1 vs. -3.0$)$, PAH (161.5 vs. $163.8 \mathrm{~cm})$, and $\mathrm{MPH}(170.8 \mathrm{vs} .167 .7 \mathrm{~cm})$.

\section{Final Adult Height}

The FAH of the treated girls was $151.3 \pm 5.1 \mathrm{~cm}$ compared to $146.8 \pm 3.8 \mathrm{~cm}$ in the untreated girls $(p=0.01)$. The FAH-SD scores of the treated and the untreated girls were $-1.4 \pm 0.6 \mathrm{SD}$ and $-2.1 \pm 0.7 \mathrm{SD}(p=0.003)$, respectively, as shown in Table 2. The FAH of the girls who were treated for $\leq 2$ years was $152.6 \pm 4.8 \mathrm{~cm}$, and the girls who were treated for $>2$ years had a FAH of $147.8 \pm 4.5 \mathrm{~cm}$ $(p=0.05)$. The FAHs of the treated and the untreated boys were $156.4 \pm 4.7 \mathrm{~cm}$ and $152.3 \pm 5.7 \mathrm{~cm}(p=0.111)$, re- 
Table 2. Outcome measures in treated and untreated ISS children by gender

\begin{tabular}{|c|c|c|c|c|c|c|}
\hline \multirow[t]{2}{*}{ Variables } & \multicolumn{3}{|l|}{ Females } & \multicolumn{3}{|l|}{ Males } \\
\hline & treated & untreated & $p$ value & treated & untreated & $p$ value \\
\hline Final adult height, SD score & $-1.4 \pm 0.6$ & $-2.1 \pm 0.7$ & 0.003 & $-1.6 \pm 0.7$ & $-2.4 \pm 0.7$ & 0.029 \\
\hline Mid-parental height, final adult height, $\mathrm{cm}$ & $4.0 \pm 5.8$ & $8.2 \pm 4.8$ & 0.033 & $14.4 \pm 5.4$ & $15.4 \pm 6.4$ & 0.735 \\
\hline $\begin{array}{l}\text { Height gain (final adult height - predicted } \\
\text { adult height at starting treatment), } \mathrm{cm}\end{array}$ & $1.6 \pm 7.8$ & $-3.6 \pm 5.7$ & 0.036 & $-5.1 \pm 13.6$ & $-11.5 \pm 8.4$ & 0.171 \\
\hline
\end{tabular}

Values are given as mean \pm SD. ISS, idiopathic short stature.

Table 3. The proportion of children who achieved their PAH, MPH, and FAH-SD score <2 SD below the population mean

\begin{tabular}{|c|c|c|c|c|c|c|}
\hline \multirow[t]{2}{*}{ Variables } & \multicolumn{3}{|c|}{ Females, $n(\%)$} & \multicolumn{3}{|c|}{ Males, $n(\%)$} \\
\hline & treated & untreated & $p$ value & treated & untreated & $p$ value \\
\hline FAH-SD score $<2$ SD* & $16(76.2)$ & $4(28.6)$ & 0.028 & $5(71.4)$ & $3(17.6)$ & 0.011 \\
\hline $\mathrm{MPH}$ & $5(23.8)$ & $0(0)$ & 0.069 & $0(0)$ & $0(0)$ & - \\
\hline PAH & $11(52.3)$ & $3(21.4)$ & 0.089 & $1(14.2)$ & $1(5.8)$ & 0.507 \\
\hline
\end{tabular}

* FAH-SD score $<2$ SD below the population mean.

$\mathrm{PAH}$, predicted adult height; MPH, mid-parental height; FAH, final adult height.

spectively. The FAH-SD scores of the treated and the untreated boys were $-1.6 \pm 0.7 \mathrm{SD}$ and $-2.4 \pm 0.7 \mathrm{SD}(p=$ 0.029 ), respectively.

\section{Outcome Measures}

The height gain (the difference between FAH and $\mathrm{PAH}$ at enrollment) in the treated girls was $1.6 \pm 7.8 \mathrm{~cm}$ and the FAH of the untreated girls was $3.6 \pm 5.7 \mathrm{~cm}$ below their $\mathrm{PAH}(p=0.036)$. However, the FAH in the treated boys was $5.1 \pm 13.6 \mathrm{~cm}$, and in the untreated boys was $11.5 \pm 8.4 \mathrm{~cm}$ below their PAH at enrollment $(p=0.171)$. The height gain in the girls who were treated for $\leq 2$ and $>2$ years was $1.1 \pm$ $5.7 \mathrm{~cm}$ and $2.9 \pm 12.2 \mathrm{~cm}$, respectively $(p=0.635)$. In the treated girls, the FAH was closer to the MPH $(p=0.033)$ compared to the untreated girls, while in boys, the mean difference between MPH and FAH in the 2 groups was statistically insignificant, as shown in Table 2.

Among the treated girls, 23.8 and $52.3 \%$ attained their $\mathrm{MPH}$ and PAH respectively. The FAH-SD score $<2$ SD below the population mean was achieved in $76.2 \%$ of our GnRHa-treated girls and in $28.6 \%$ of the untreated girls $(p=0.028)$. In the treated boys, 5 patients $(71.4 \%)$ achieved an FAH-SD score $<2$ SD below the population mean $(p=0.011)$ and 1 participant achieved his $\mathrm{PAH}$ as shown in Table 3.

\section{Multivariate Regression}

Multivariate linear regression showed that $\mathrm{MPH}$, age, $\mathrm{BA}, \mathrm{PAH}$, and height-SD at presentation were not statistically and significantly different and therefore, they were excluded from the model. GnRHa therapy is the only variable that had a statistically significant correlation with height gain after adjustment for potential confounding variables $(p=0.028)$.

\section{Discussion}

This study evaluated the growth-promoting effect of GnRHa among children with ISS in comparison with a control group through assessing variable outcome measures such as FAH, height gain, FAH-SD score and the proportion of patients who achieved their $\mathrm{PAH}, \mathrm{MPH}$, and a FAH-SD score $<2$ SD below the population mean. 
Few studies have assessed the statural benefits of GnRHa therapy alone in children with ISS [15-18]. Moreover, some studies did not include a control group $[15,17]$ and data on the FAH are lacking [15-17].

Based on our cohort of 59 children, GnRHa therapy for $1.8 \pm 1.0$ years $(1.3 \pm 0.3$ years for boys vs. $2.0 \pm 1.1$ years for girls; $p=0.182$ ) significantly improved the FAH and height gain among treated girls. In boys, $\mathrm{GnRHa}$ treatment improved the FAH-SD score significantly, and a FAH-SD score $<2$ SD below the population mean was achieved in $71.4 \%$ of the treated and in $17.6 \%$ of the untreated boys $(p=0.011)$. However, GnRHa treatment in boys brought about a small increase in height gain and FAH that failed to achieve statistical significance. This insignificant increase in FAH and height gain could be related to the small number of the treated boys or to the lack of the effect of GnRHa therapy in boys with ISS. Contrary to studies on short stature referral and growth, caregivers were more likely to accept GnRHa treatment for females $[10,11]$. This may be attributable to the social norms in our culture, as short females are less likely to get married, while this is not true for males. Kohn et al. [26] previously reported this gender-specific difference in a study that evaluated the effect of combined GH and GnRHa therapy in a mixed group of GH-deficient children and children with ISS. Girls with normal puberty had significant height gain $(3.0 \pm 6.1 \mathrm{~cm} ; p<0.001)$, but in boys there was no statistically significant increase in height gain (1.3 $\pm 6.8 \mathrm{~cm}$ ) [26]. Another study that assessed the effects of adding $\mathrm{GnRH}$ a to $\mathrm{GH}$ therapy in $\mathrm{GH}$-deficient children showed that the FAH of girls, but not boys significantly surpassed their PAH [27]. This superior response in females may be related to faster epiphyseal fusion driven by estrogen [27]. In addition, pubertal suppression in boys may have different effects on growth as pubertal growth is driven by aromatization of testosterone to estrogen and by increased levels of GH [28].

Our results showed that GnRHa in girls with ISS significantly improved FAH and FAH-SD score. FAH-SD score $<2$ SD below the population mean was achieved in $76.2 \%$ of our GnRHa treated girls and $28.6 \%$ of the untreated girls $(p=0.028)$. Our results were comparable with those obtained from a randomized subset of 49 adolescents with short stature treated with GnRHa for $3.5 \pm$ 0.9 years by Yanovski et al. [18]. Those who received treatment were significantly taller. Also, 52 and $28 \%$ of GnRHa-treated and -untreated participants, respectively, had an FAH-SD score $<2$ SD below the population mean [18]. Similarly, in the preliminary results of a randomized double blind clinical trial that included 16 adolescents with short stature, Municchi et al. [16] showed that 4 years of therapy with GnRHa increased PAH at the end of the treatment by $7.2 \mathrm{~cm}$ in comparison to pretreatment height $(p=0.05)$ and by $10.9 \mathrm{~cm}$ compared to untreated subjects $(p=0.05)$.

Contrary to our findings, Lindner et al. [15] showed that 2 years of GnRHa treatment in 8 boys and 9 girls with ISS decreased height-SD score caused no significant improvement in predicted adult stature as a result of reduced growth velocity during the post treatment year. Carel et al. [17] treated 31 girls with constitutional short stature with GnRHa for $23 \pm 4$ months; the near final height of treated girls was $149.1 \pm 4 \mathrm{~cm}$, their final height prognosis was $1.2 \pm 2.2 \mathrm{~cm}$ below their predicted height at the end of the treatment $(p<0.01)$ and their height SD score decreased from $-2.3 \pm 0.9$ to $-2.7 \pm 0.7 \mathrm{SD}(p<$ $0.0001)$ during treatment [17].

The difference between FAH and PAH at enrollment (known as height gain) has frequently been used as a criteria of the effectiveness of the growth-promoting therapy. In our study, the height gain was significantly higher in the treated girls compared to those untreated $(p=$ 0.036 ); the treated girls achieved their PAH and even surpassed it by $1.6 \pm 7.8 \mathrm{~cm}(p=0.036)$, and $52.3 \%$ of them attained their $\mathrm{PAH}$, as shown in Table 3 . The large SD of the height gain, irrespective of the treated gender (1.6 \pm 7.8 and $-5.1 \pm 13.6 \mathrm{~cm}$ in girls and boys respectively), is an evidence for the inter-individual variability in FAH response to GnRHa therapy. This variability in response was also evident in several outcome studies of GH therapy in children with ISS $[5,10,11]$.

Our findings are in agreement with those of the study by Yanovski et al. [18] as the height gain was significantly higher for treated children compared to untreated children $(4.2 \pm 4.5$ vs. $0.5 \pm 4.1 \mathrm{~cm}, p=0.004)$. However, the height gain in our treated girls was less than that reported by Yanovski et al. [18] (1.6 vs. $4.2 \mathrm{~cm}$ ). This difference could be related to heterogeneity in the population studied as only $50 \%$ of the treated subjects had ISS. Also, this difference could be attributed to the apparent effect of $\mathrm{GH}$ therapy, as the height gain in $\mathrm{GH}$-treated children was $0.4 \pm 0.6$ greater than GH-untreated children $(p=$ 0.004) [18]. Furthermore, a longer duration of GnRHa therapy will result in a prolonged duration of arrested bone maturation, prolonged growth periods, and subsequently more height gain $[17,18]$. Among our treated girls, 15 received treatment for $\leq 2$ years and 6 received treatments for $>2$ years. The FAHs of the girls treated for $\leq 2$ and $>2$ years were $152.6 \pm 4.8$ and $147.8 \pm 4.5 \mathrm{~cm}(p=$ $0.05)$, respectively. The height gain in girls who were 
Table 4. The effect of GnRHa therapy in children with idiopathic short stature and normal puberty in previous studies

\begin{tabular}{|c|c|c|c|c|c|}
\hline Reference & Study population & $\begin{array}{l}\text { Age at onset } \\
\text { of treatment, } \\
\text { years, mean } \pm S D\end{array}$ & $\begin{array}{l}\text { Duration } \\
\text { of therapy, } \\
\text { years, mean } \pm S D\end{array}$ & Statural outcomes & $p$ value \\
\hline $\begin{array}{l}\text { Municchi } \\
\text { et al. [16] }\end{array}$ & $\begin{array}{l}\text { Treated: } 9 \\
\text { Untreated: } 7\end{array}$ & $12.2 \pm 1.0$ & 4.0 & $\begin{array}{l}\text { PAH after } 4 \text { years* } \\
\text { Increased by } 7.2 \mathrm{~cm} \text { compared to } \\
\text { baseline } \\
\text { Increased by } 10.9 \mathrm{~cm} \text { compared to } \\
\text { untreated }\end{array}$ & $\begin{array}{l}<0.005 \\
<0.005\end{array}$ \\
\hline $\begin{array}{l}\text { Carel } \\
\text { et al. [17] }\end{array}$ & Treated: 31 girls & $11.9 \pm 1.1$ & $1.9 \pm 0.3$ & $\begin{array}{l}\text { Near FAH: } 149.1 \pm 4 \mathrm{~cm} \\
\text { PAH after } 4.45 \text { years: } \\
\text { Increased by } 1 \pm 2.3 \mathrm{~cm} \text { compared } \\
\text { to baseline } \\
\text { Decreased by } 1.2 \pm 2.2 \mathrm{~cm} \text { compared } \\
\text { to end of therapy }\end{array}$ & $\begin{array}{l}<0.02 \\
<0.01\end{array}$ \\
\hline $\begin{array}{l}\text { Current } \\
\text { study }\end{array}$ & $\begin{array}{l}\text { Treated: } 28 \text { ( } 21 \text { girls, } 7 \text { boys) } \\
\text { Untreated: } 31 \text { (14 girls, } 17 \text { boys) }\end{array}$ & $\begin{array}{l}\text { Girls: } 10.9 \pm 1.4 \\
\text { Boys: } 12.6 \pm 1.7\end{array}$ & $1.8 \pm 1.0$ & $\begin{array}{l}\text { FAH } \\
\text { Treated girls: } 151.3 \pm 5.1 \mathrm{~cm} \\
\text { Untreated girls: } 146.8 \pm 3.8 \mathrm{~cm} \\
\text { Treated boys: } 156.4 \pm 4.7 \mathrm{~cm} \\
\text { Untreated boys: } 152.3 \pm 5.7 \mathrm{~cm} \\
\text { Height gain } \\
\text { Treated girls: } 1.6 \pm 7.8 \mathrm{~cm} \\
\text { Untreated girls: }-3.6 \pm 5.7 \mathrm{~cm} \\
\text { Treated boys: }-5.1 \pm 13.6 \mathrm{~cm} \\
\text { Untreated boys: }-11.5 \pm 8.4 \mathrm{~cm}\end{array}$ & $\begin{array}{l}0.01 \\
0.11\end{array}$ \\
\hline
\end{tabular}

* PAH, predicted adult height.

** FAH, final adult height.

treated for $\leq 2$ and $>2$ years was $1.1 \pm 5.7$ and $2.9 \pm 12.2$ $\mathrm{cm}(p=0.635)$, respectively. We cannot conclude that the duration of treatment made no difference, as the girls who were treated for $\leq 2$ years were taller at presentation than those treated for $>2$ years $(137.2 \pm 4.5$ vs. $126.2 \pm 9.7$ $\mathrm{cm} ; p=0.002)$. However, in the study by Carel et al. [17], the effect of GnRHa therapy on height gain was limited.

Despite the notable improvement in the final height outcome, the mean FAHs of the treated and the untreated girls were still below their MPH by 4.0 and $8.2 \mathrm{~cm}(p=$ $0.033)$, respectively. Similarly, in Yanovski et al. [18] cohort, the FAH was lower than the MPH in both treatment groups [18]. Additionally, the absence of correlation be- tween height gain and BA among our treated girls ( $p=$ $0.406)$ was previously reported [16-18].

It is obvious that the diversity in the reported results may be linked to the differences in the end points used and to the duration of treatment, as shown in Table 4. It may also be related to the variability of individual responses, as several other factors such as genetic height potentials, and nutritional and psychological status could influence FAH.

These findings highlight the modest effect of GnRHa therapy outside the context of precocious puberty that is limited to $4 \mathrm{~cm}$ [15-18]. This modest effect is almost comparable to that reported by GH outcome studies in children with ISS, as GH therapy for approximately 5 years 
improved adult height by $5 \mathrm{~cm}$ [10]. The estimated annual cost of GH treatment in children with ISS is USD $5,000-40,000$ [29]. In Jordan, the yearly cost of GnRHa is approximately 2,500 USD. The cost of any growth-promoting therapy in children with ISS should be taken in consideration to the background modest effect on adult height and the remarkable variability of individual responses $[10,11]$. However, pubertal growth should not be hindered after the age of 14-15 years in order to avoid anxiety and psychological distress $[17,30]$.

To our knowledge, this is the only study in the region that evaluates the growth benefit of GnRHa among children with ISS. The strength of our study depends on the fact that our patients were followed up until they achieved their FAH, which is unusual in pediatric studies [15-17]. The Pediatric Endocrine Society considered FAH as the primary outcome in consideration to the efficacy of GH treatment in children [10]. Moreover, including a control group, a mixed population of male and female subjects, addressing gender differences in response to GnRHa, and the inclusion of several outcome measures will add more strength to the current study.

The current study is limited by the small sample size particularly of the boys treated with GnRHa. The design of the study is another limiting factor, as the effectiveness of GnRHa in improving FAH in children with ISS can be more definitively assessed by a prospective randomized controlled study. Another limitation of this study is lack of assessment of the psychological burden of short stature and the psychosocial impact of GnRHa therapy. Finally, several other factors could influence FAH in children with ISS as genetic height potentials, and nutritional and psychological status.

\section{Conclusion}

GnRHa therapy has a modest effect in improving FAH and height gain in adolescent ISS females with large interindividual variability. In males, our data do not support the use of GnRHa treatment to ameliorate short stature. The cost of GnRHa treatment in children with ISS should be taken into consideration, with individual assessment of physical and psychological burdens in the background of the remarkable variability of adult height response. Further large-scale randomized controlled trials are required to evaluate bone mineral density, emotional, psychological and social sequel of postponing normal puberty and verify this gender-related discrepancy in delaying normal puberty as a component of growth-promoting therapy.

\section{Statement of Ethics}

Our historical cohort study was conducted after obtaining approval from the Ethics Committee of the National Center for Diabetes Endocrinology and Genetics, which is accredited by the National Ethics Committee. Also, the study was conducted in accordance with the Declaration of Helsinki. As we used routinely generated data with no identifying information, the study carries no harm whatsoever to patients. Data were used only for scientific purposes.

\section{Disclosure Statement}

The authors declare that they have no conflicts of interest to disclose.

\section{References}

1 Quitmann JH, Bullinger M, Sommer R, Rohenkohl AC, Bernardino Da Silva NM. Associations between psychological problems and quality of life in pediatric short stature from patients' and parents' perspectives. PLoS One. 2016 Apr;11(4):e0153953.

2 Holmes CS, Hayford JT, Thompson RG. Parents' and teachers' differing views of short children's behaviour. Child Care Health Dev. 1982 Nov-Dec;8(6):327-36.

3 Sandberg DE, Brook AE, Campos SP. Short stature: a psychosocial burden requiring growth hormone therapy? Pediatrics. 1994 Dec;94(6 Pt 1):832-40.
4 Sandberg DE, Voss LD. The psychosocial consequences of short stature: a review of the evidence. Best Pract Res Clin Endocrinol Metab. 2002 Sep;16(3):449-63.

5 Cohen P, Rogol AD, Deal CL, Saenger P, Reiter EO, Ross JL, et al.; 2007 ISS Consensus Workshop participants. Consensus statement on the diagnosis and treatment of children with idiopathic short stature: a summary of the Growth Hormone Research Society, the Lawson Wilkins Pediatric Endocrine Society, and the European Society for Paediatric Endocrinology Workshop. J Clin Endocrinol Metab. 2008 Nov;93(11):4210-7.
6 Lindsay R, Feldkamp M, Harris D, Robertson J, Rallison M. Utah Growth Study: growth standards and the prevalence of growth hormone deficiency. J Pediatr. 1994 Jul;125(1): 29-35.

7 Soliman A, De Sanctis V, Elalaily R, Bedair S. Advances in pubertal growth and factors influencing it: can we increase pubertal growth? Indian J Endocrinol Metab. 2014 Nov;18(7 Suppl 1):S53-62.

8 Carel JC. Can we increase adolescent growth? Eur J Endocrinol. 2004;151:U101-8.

9 Wit JM, Oostdijk W. Novel approaches to short stature therapy. Best Pract Res Clin Endocrinol Metab. 2015 Jun;29(3):353-66. 
10 Grimberg A, DiVall SA, Polychronakos C, Allen DB, Cohen LE, Quintos JB, et al.; Drug and Therapeutics Committee and Ethics Committee of the Pediatric Endocrine Society. Guidelines for growth hormone and insulinlike growth factor-I treatment in children and adolescents: growth hormone deficiency, idiopathic short stature, and primary insulinlike growth factor-I deficiency. Horm Res Paediatr. 2016;86(6):361-97.

11 Wit JM, Reiter EO, Ross JL, Saenger PH, Savage $\mathrm{MO}$, Rogol $\mathrm{AD}$, et al. Idiopathic short stature: management and growth hormone treatment. Growth Horm IGF Res. 2008 Apr; 18(2):111-35.

12 Guaraldi F, Beccuti G, Gori D, Ghizzoni L. Management of endocrine disease: long-term outcomes of the treatment of central precocious puberty. Eur J Endocrinol. 2016 Mar; 174(3):R79-87.

13 Uriarte MM, Baron J, Garcia HB, Barnes KM, Loriaux DL, Cutler GB Jr. The effect of pubertal delay on adult height in men with isolated hypogonadotropic hypogonadism. J Clin Endocrinol Metab. 1992 Feb;74(2):436-40.

14 Bilezikian JP, Morishima A, Bell J, Grumbach MM. Increased bone mass as a result of estrogen therapy in a man with aromatase deficiency. N Engl J Med. 1998 Aug;339(9):599-603.

15 Lindner D, Job JC, Chaussain JL. Failure to improve height prediction in short-stature pubertal adolescents by inhibiting puberty with luteinizing hormone-releasing hormone analogue. Eur J Pediatr. 1993 May;152(5): 393-6.
16 Municchi G, Rose SR, Pescovitz OH, Barnes KM, Cassorla FG, Cutler GB Jr. Effect of deslorelin-induced pubertal delay on the growth of adolescents with short stature and normally timed puberty: preliminary results. J Clin Endocrinol Metab. 1993 Nov;77(5):1334-9.

17 Carel JC, Hay F, Coutant R, Rodrigue D, Chaussain JL. Gonadotropin-releasing hormone agonist treatment of girls with constitutional short stature and normal pubertal development. J Clin Endocrinol Metab. 1996 Sep;81(9):3318-22.

18 Yanovski JA, Rose SR, Municchi G, Pescovitz $\mathrm{OH}$, Hill SC, Cassorla FG, et al. Treatment with a luteinizing hormone-releasing hormone agonist in adolescents with short stature. N Engl J Med. 2003 Mar;348(10):908-17.

19 Watson SE, Greene A, Lewis K, Eugster EA. Bird's-eye view of GnRH analog use in a pediatric endocrinology referral center. Endocr Pract. 2015 Jun;21(6):586-9.

20 Swaiss HH, Khawaja NM, Farahid $\mathrm{OH}, \mathrm{Ba}-$ tieha AM, Ajlouni KM. Effect of gonadotropin-releasing hormone analogue on final adult height among Jordanian children with precocious puberty. Saudi Med J. 2017 Nov; 38(11):1101-7.

21 Clayton PE, Cuneo RC, Juul A, Monson JP, Shalet SM, Tauber M; European Society of Paediatric Endocrinology. Consensus statement on the management of the GH-treated adolescent in the transition to adult care. Eur J Endocrinol. 2005 Feb;152(2):165-70.
22 Greulich WW, Pyle SI. Radiographic Atlas of Skeletal Development of the Hand and Wrist. Am J Med Sci. 1959;238(3):393.

23 Marshall WA, Tanner JM. Variations in pattern of pubertal changes in girls. Arch Dis Child. 1969 Jun;44(235):291-303.

24 Marshall WA, Tanner JM. Variations in the pattern of pubertal changes in boys. Arch Dis Child. 1970 Feb;45(239):13-23.

25 Bayley N, Pinneau SR. Tables for predicting adult height from skeletal age: revised for use with the Greulich-Pyle hand standards. J Pediatr. 1952 Apr;40(4):423-41.

26 Kohn B, Julius JR, Blethen SL. Combined use of growth hormone and gonadotropin-releasing hormone analogues: the national cooperative growth study experience. Pediatrics. 1999 Oct;104(4 Pt 2):1014-8.

27 Tauber M, Berro B, Delagnes V, Lounis N, Jouret B, Pienkowski C, et al. Can some growth hormone $(\mathrm{GH})$-deficient children benefit from combined therapy with gonadotropin-releasing hormone analogs and $\mathrm{GH}$ ? Results of a retrospective study. J Clin Endocrinol Metab. 2003 Mar;88(3):1179-83.

28 Abbassi V. Growth and normal puberty. Pediatrics. 1998 Aug;102(2 Pt 3):507-11.

29 Freemark M. Editorial: Growth hormone treatment of "idiopathic short stature": not so fast. J Clin Endocrinol Metab. 2004 Jul;89(7): 3138-9.

30 Wit JM, Balen HV, Kamp GA, Oostdijk W. Benefit of postponing normal puberty for improving final height. Eur J Endocrinol. 2004 Aug;151(Suppl 1):S41-5. 